\title{
Textile Research Journal
}

http://trj.sagepub.com

\section{Fabrics Made from Non-conventional Blends: What Can We Expect from them Related to Frictional Properties? \\ Mário Lima, Rosa M. Vasconcelos, Luís F Silva and Joana Cunha \\ Textile Research Journal 2009; 79; 337 \\ DOI: $10.1177 / 0040517508097519$}

The online version of this article can be found at:

http://trj.sagepub.com/cgi/content/abstract/79/4/337

\author{
Published by: \\ (SAGE \\ http://www.sagepublications.com
}

Additional services and information for Textile Research Journal can be found at:

Email Alerts: http://trj.sagepub.com/cgi/alerts

Subscriptions: http://trj.sagepub.com/subscriptions

Reprints: http://www.sagepub.com/journalsReprints.nav

Permissions: http://www.sagepub.co.uk/journalsPermissions.nav

Citations http://trj.sagepub.com/cgi/content/refs/79/4/337 


\section{Fabrics Made from Non-conventional Blends: What Can We Expect from them Related to Frictional Properties?}

\begin{abstract}
This paper briefly describes a novel patented laboratory equipment, which was studied, designed, and manufactured at the University of Minho, Portugal, based on a new method of accessing friction coefficient of fabrics and other two-dimensional non-rigid surfaces, as well as its fundamentals and working principle. An experimental study was carried out in order to compare fabrics produced with a new generation of fibers, namely polylatic acid (PLA) fiber and soya protein fiber (SPF). A 5- satin structure weave was used in the double-faced fabrics' construction in both sides, allowing us to test the influence of each fiber in the friction properties. The results of the experimental work were analyzed using various tools, including SPSS15. $0^{\circledR}$ statistical package and commented in the light of the influence of the raw material in the friction properties of the fabrics. The soft felling of the SPF was confirmed as expected, as well as the roughness of the PLA fiber.
\end{abstract}

Key words FRICTORQ, friction coefficient, Non-conventional blends

\author{
Mário Lima ${ }^{1, *}$, Rosa M. Vasconcelos ${ }^{2}$. \\ Luís F. Silva' and Joana Cunha ${ }^{2}$ \\ ${ }^{1}$ Department of Mechanical Engineering. University of \\ Minho, 4800-058 Guimarães, Portugal \\ ${ }^{2}$ Department of Textile Engineering. University of Minho. \\ 4800-058 Guimarães, Portugal
}

The way humans sense and interact with textile materials is closely related to their performance properties [1, 2], particularly in the case of those materials that are worn in contact with the skin, such as clothing, home textiles, furnishings, and automotive fabrics. The importance of fabric coefficient of friction is confirmed by the number of scientific studies carried out in the past on this subject [3-7]. Recently, new laboratory equipment was proposed, based on a new method of assessing the friction coefficient of fabrics, which is easy to use and very precise. Several previous studies were performed in order to find a relationship between friction coefficient, as measured with FRICTORQ, and fabric friction properties measured by other instruments and other surface evaluations based on subjective assessments. It is possible to name the following: a comparative study with Kawabata Evaluation System (KES) friction [8] and another comparative study with fabric weave structure using subjective assessment [9]. All these studies have consistently led to the conclusion that higher fabric friction coefficients correspond to smoother surfaces. In the comparison with KES, it was also possible to notice that the dispersion of results was lower with FRICTORQ than with KES friction. The development and validation of FRICTORQ as reliable test equipment [10] justifies experimental work with a set of fabrics made from non-conventional fiber combinations.

Currently, the main fiber research is pointing towards materials that present lower environmental impact, which can improve final fabric performance. Hence, the new mixtures under study are a reflection of these trends.

One of the new fibers used in the mixtures under evaluation is the polylatic acid (PLA) fiber, which has the following

\footnotetext{
* Corresponding author: Department of Mechanical Engineering, University of Minho, 4800-058 Guimarães, Portugal. e-mail: mlima@dem.uminho.pt
} 
main advantages: cotton look appearance, environmentally friendly as it is based on a natural polymer being therefore biodegradable, and high resistance to UV rays [11]. PLA fiber is composed of at least $85 \%$ by weight of lactic acid ester units derived from naturally occurring sugars. Its use is not yet widespread, but the fact that it is an ecological fiber represents an important factor for its use in blends. When mixed with other fibers [12], PLA fiber also presents a good performance, specifically:

- Natural fiber hand;

- Wickability/breathability of natural fibers;

- Good flammability resistance;

- Excellent drapeability.

The other new fiber used in the studied mixtures is soya protein fiber (SPF). SPF is a fiber produced by a wet spinning process that takes place after the extraction of spherical protein from soybean residue. According to the manufacturers [13], the content of protein in the SPF is up to $45 \%$ and the fiber contains 18 amino acids. The soft touch that this fiber presents is one of its most attractive properties. In fact, producers [14] claim that SPF has the softness and smoothness of cashmere and is not hazardous to the environment. It also exhibits good moisture absorption properties, giving fabrics better comfort characteristics when mixed with other fibers, presents good ventilation properties, as well as draping and warmth superior to other high quality fibers $[14,15]$.

\section{The Model of FRICTORQ}

The evolution of the FRICTORQ instrument is summarized in Figures 1 and 2. It comprises a torque sensor, with the respective data acquisition system, a DC motor with a cinematic chain (gears and timing belt) to drive the lower fabric sample, and a software package designed specifically for this application. This is a new method used by us to determine the coefficient of friction of textile fabrics, based on the dry clutch principle, where an annular-shaped flat upper body (kept still during the whole test procedure) rubs against a lower flat surface, which rotates around a vertical axis at a constant angular velocity. Contact pressure is constant, given by the ratio between the own weight of the upper body and the contact area. The signal acquired by the torque sensor is digitalized through an electronic interface and fed into a PC where friction coefficient is computed. This first testing set-up, named FRICTORQ I, is highlighted in Figure 1 $[16,17]$.

This model went through various developmental stages and some of the detected weaknesses suggested that a different approach could be explored. Nevertheless, the rotary action remained, but the contact is now restricted to three small special elements (feet), radially disposed at $120^{\circ}$. Providing a relative displacement of approximately $90^{\circ}$, it is assured that a new portion of fabric is always moved under these contact elements. Other design details and the adopted theoretical model for the development of the sec-
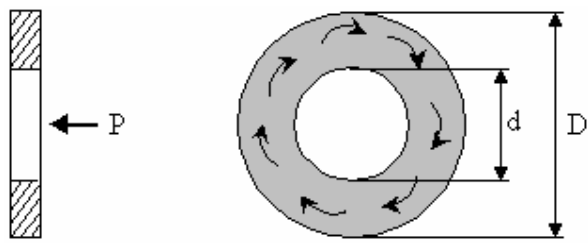

(A)

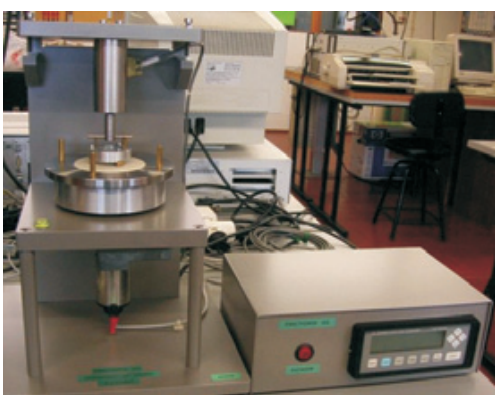

(A)
(B)
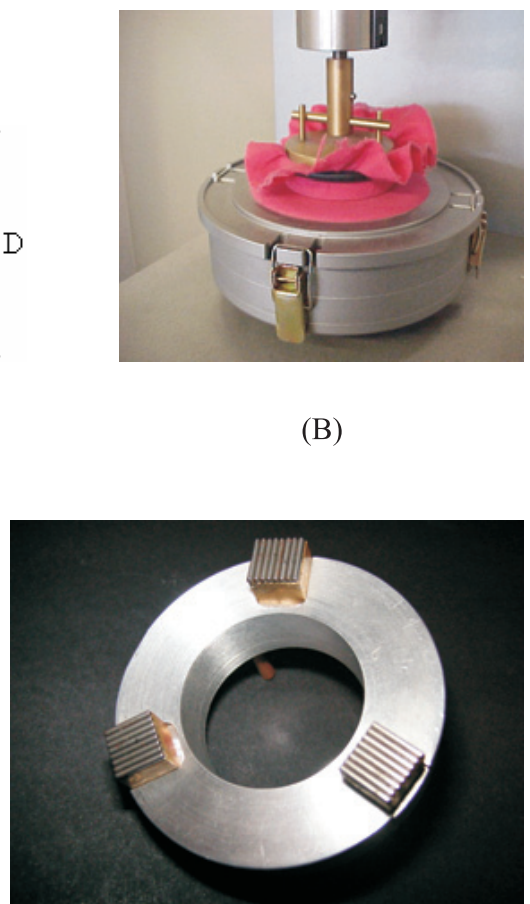

(B)
Figure 1 (A) Geometry of the first adopted theoretical model for the FRICTORQ I; (B) first developed FRICTORQ set-up showing a detailed view of the positioning and tightening fabric clamps.

Figure 2 (A) FRICTORQ II: (B) the upper body (or contact sensor) with three small pads, disposed at 120 


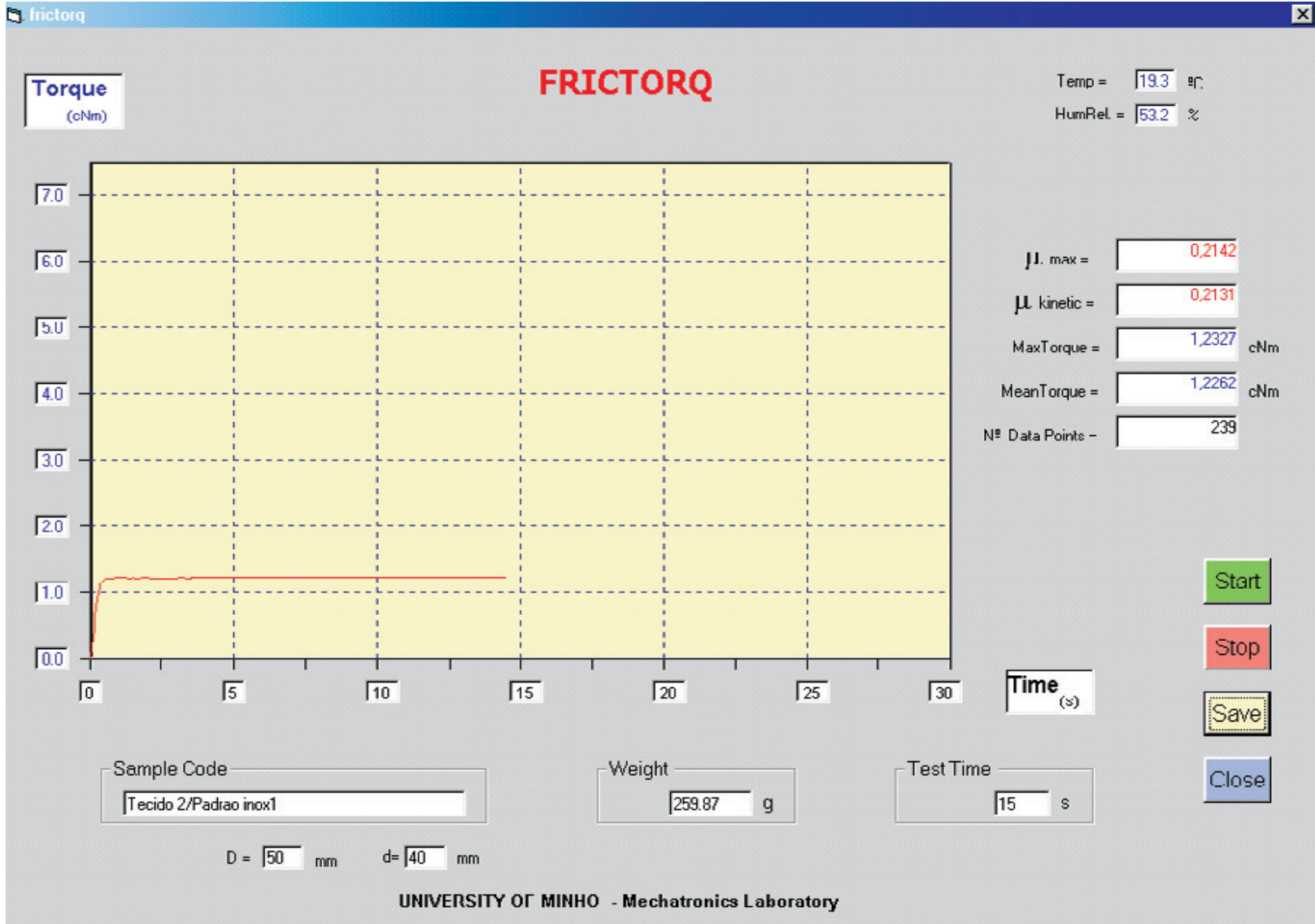

Figure 3 Typical output display and main front panel of the software package developed for this application.

ond FRICTORQ set-up, named FRICTORQ II, are depicted elsewhere $[18,19]$.

Figure 2 highlights the latest test set-up, as well as a detailed view of the upper body (or contact sensor) that includes three small pads with an approximately square shape, covered by a number of calibrated steel needles of $1 \mathrm{~mm}$ diameter.

Figure 3 presents a typical output display, showing the most relevant parameters acquired on a simple friction test. Data acquired between 5 and 20 seconds of the experiment were used for computing the kinetic or dynamic friction coefficient of the tested fabric samples.

\section{Experimental Procedure}

\section{Characterization of the Tested Materials}

The tested materials were three double-faced fabrics made from non-conventional fiber combinations listed as follows:
1. cotton-corn fiber (CO-PLA)

2. polyester/cotton-cotton (PES/CO-CO)

3. cotton-soya protein fiber (CO-SPF)

These fabrics had a satin base structure, shown in Figure 4, meaning that each material was mainly in one of the fabric's faces, which meant that, for example, in the $\mathrm{CO}$ SPF fabric, the outer face (OF) presented the $\mathrm{CO}$ as the main contact fiber material (odd weft insertions), while in the inner face (IF) was SPF weft the only one that was shown (even weft insertions).

The double-faced fabric samples were produced in the same loom, in sequence, so as to maintain the same warp in all of them, and to avoid differences in the construction parameters, being the warp always cotton. Therefore, all the samples presented the same yarn densities, both for the warp as for the weft. Table 1 presents the main dimensional properties of the fabrics.

The use of these double-faced structures allowed us to test the influence of each fiber in friction properties. 
Table 1 Dimensional properties of fabrics.

\section{Properties}

\begin{tabular}{|c|c|c|c|c|c|c|c|c|}
\hline Fabric & $\begin{array}{c}\text { Blend } \\
\text { composition } \\
(\%)\end{array}$ & $\begin{array}{l}\text { Thickness } \\
(\mathrm{mm})\end{array}$ & $\begin{array}{l}\text { Weight/unit } \\
\text { area } \\
\left(\mathrm{g} / \mathrm{m}^{2}\right)\end{array}$ & $\begin{array}{c}\text { Warp } \\
\text { yarns/cm }\end{array}$ & $\begin{array}{c}\text { Weft } \\
\text { yarns/cm }\end{array}$ & $\begin{array}{l}\text { Warp yarn } \\
\text { (Ne) }\end{array}$ & $\begin{array}{l}\text { Weft yarn } \\
\text { OF }(\mathrm{Ne})\end{array}$ & $\begin{array}{l}\text { Weft yarn } \\
\text { IF (Ne) }\end{array}$ \\
\hline $\begin{array}{l}\text { Cotton-corn fiber } \\
\text { (CO-PLA) }\end{array}$ & $\begin{array}{l}\text { 81.19 CO } \\
18.81 \text { PLA }\end{array}$ & 0.377 & 126.48 & 76 & 34 & 50 & 50 & 40 \\
\hline $\begin{array}{l}\text { Polyester/cotton-cotton } \\
\text { (PES/CO-CO) }\end{array}$ & $\begin{array}{l}80.00 \mathrm{CO} \\
20.00 \mathrm{PES}\end{array}$ & 0.417 & 136.84 & 76 & 34 & 50 & 30 & 50 \\
\hline $\begin{array}{l}\text { Cotton-soya protein fiber } \\
\text { (CO-SPF) }\end{array}$ & $\begin{array}{l}81.05 \mathrm{CO} \\
18.95 \mathrm{SPF}\end{array}$ & 0.415 & 126.98 & 76 & 34 & 50 & 50 & 40 \\
\hline
\end{tabular}

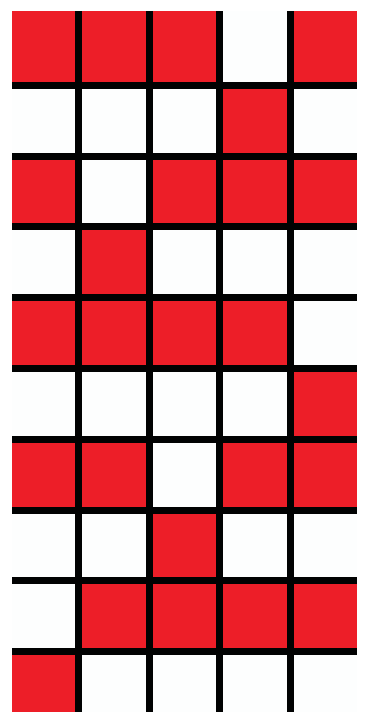

Figure 4 Weave structure.

\section{Methodology}

FRICTORQ II instrument was used to test the OF and IF surfaces of the materials. Samples were prepared, cut in circles of $113 \mathrm{~mm}$ diameter, and tested under a conditioned atmosphere of $20 \pm 2{ }^{\circ} \mathrm{C}$ and $65 \pm 2 \% \mathrm{RH}$.

\section{Results and Discussion}

The data obtained during the tests carried out using FRICTORQ II testing apparatus were analyzed using the statistical package SPSS $15.0^{\circledR}$ in order to study the influence of the different materials in the friction coefficient. Table 2 shows the results obtained in the descriptive statistics for friction coefficient of the tested materials.

As can be verified in Table 2, the mean values ranged between 0.196 and 0.212 , with the minimum value obtained in CO-PLA_IF and the maximum in CO-SPF_OF. In Figure 5 , the results obtained from the tests are presented in a boxplot chart.

The lowest amplitude value was achieved for CO-PLA_ OF sample and the highest for the CO-SPF_OF.

Table 2 Descriptive statistics.

\begin{tabular}{|c|c|c|c|c|c|c|c|c|}
\hline & \multirow{2}{*}{$\mathrm{N}$} & \multirow{2}{*}{ Mean } & \multirow{2}{*}{$\begin{array}{l}\text { Standard } \\
\text { deviation }\end{array}$} & \multirow{2}{*}{$\begin{array}{l}\text { Standard } \\
\text { error }\end{array}$} & \multicolumn{2}{|c|}{$\begin{array}{l}95 \% \text { confidence interval } \\
\text { for mean }\end{array}$} & \multirow{2}{*}{ Minimum } & \multirow{2}{*}{ Maximum } \\
\hline & & & & & $\begin{array}{l}\text { Lower } \\
\text { boundary }\end{array}$ & $\begin{array}{l}\text { Upper } \\
\text { boundary }\end{array}$ & & \\
\hline CO-PLA_IF & 13 & 0.196 & 0.0035090 & 0.0009732 & 0.194 & 0.198 & 0.191 & 0.203 \\
\hline PES/CO-CO_IF & 13 & 0.207 & 0.0035382 & 0.0009813 & 0.205 & 0.209 & 0.203 & 0.213 \\
\hline CO-SPF_IF & 13 & 0.205 & 0.0035744 & 0.0009914 & 0.202 & 0.207 & 0.198 & 0.211 \\
\hline CO-PLA_OF & 13 & 0.197 & 0.0022623 & 0.0006275 & 0.196 & 0.199 & 0.192 & 0.201 \\
\hline PES/CO-CO_OF & 13 & 0.206 & 0.0023241 & 0.0006446 & 0.205 & 0.208 & 0.203 & 0.211 \\
\hline CO-SPF_OF & 13 & 0.212 & 0.0042068 & 0.0011668 & 0.209 & 0.214 & 0.204 & 0.218 \\
\hline Total & 78 & 0.204 & 0.0064628 & 0.0007318 & 0.202 & 0.205 & 0.191 & 0.218 \\
\hline
\end{tabular}


Figure 5 Boxplot results.

Table 3 Scheffe analysis for $\mu_{\text {kin }}$.

\begin{tabular}{lcccc} 
& & \multicolumn{3}{c}{ Subset for alpha $=0.05$} \\
\cline { 3 - 5 } Samples & & 1 & 2 & 3 \\
\hline CO-PLA_IF & 13 & 0.196 & & \\
CO-PLA_OF & 13 & 0.197 & & \\
CO-SPF_IF & 13 & & 0.205 & \\
PES/CO-CO_OF & 13 & & 0.206 & \\
PES/CO-CO_IF & 13 & & 0.207 & \\
CO-SPF_OF & 13 & & & 0.212 \\
Significance & & 0.942 & 0.523 & 1.000 \\
\hline
\end{tabular}

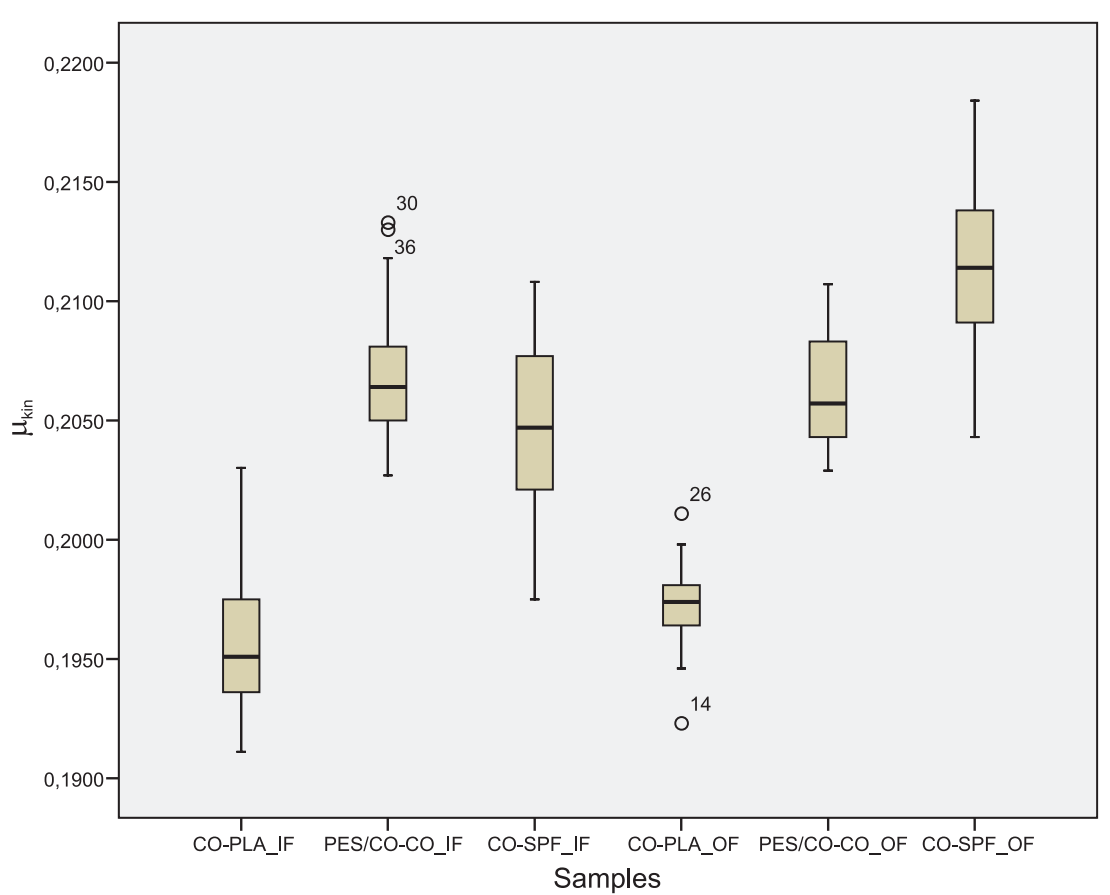

In order to compare the results obtained from the six tested materials, a Scheffe analysis was carried out to determine the existence of homogeneous subsets. Means for groups in homogeneous subsets are displayed in Table 3.

The analysis clearly determined the existence of three different subsets. In order to analyze in more depth the results obtained in the Scheffe test, the multiple comparison analysis table was carefully reviewed and Table 4 was constructed presenting only the mean difference significance of the ANOVA comparison. This brought to our attention the significance obtained between CO-SPF_OF and PES/COCO_IF, which was 0.048 , very near the 0.05 level of significance in which the test was carried out.

Table 4 Mean difference significance of the ANOVA comparison.

\begin{tabular}{|c|c|c|c|c|c|c|}
\hline Sample & CO-PLA_IF & CO-PLA_OF & PES/CO-CO_IF & PES/CO-CO_OF & CO-SPF_IF & CO-SPF_OF \\
\hline \multicolumn{7}{|l|}{ CO-PLA_IF } \\
\hline CO-PLA_OF & 0.942 & & & & & \\
\hline PES/CO-CO_IF & $0.000\left(^{*}\right)$ & $0.000\left(^{*}\right)$ & & & & \\
\hline PES/CO-CO_OF & $0.000\left(^{*}\right)$ & $\left.0.000{ }^{*}\right)$ & 0.990 & & & \\
\hline CO-SPF_IF & $\left.0.000{ }^{*}\right)$ & $\left.0.000{ }^{*}\right)$ & 0.523 & 0.885 & & \\
\hline CO-SPF_OF & $0.000\left(^{*}\right)$ & $0.000(*)$ & $0.048(*)$ & $0.007\left(^{*}\right)$ & $0.000\left(^{*}\right)$ & \\
\hline
\end{tabular}

$\left(^{*}\right)$ The mean difference was significant at the 0.05 level. 


\section{Conclusions}

This study allowed us to draw the following conclusions about the friction behavior of the non-conventional blends:

- PLA fiber had a strong influence on friction, independent of being on the outer or on the inner face of the fabric, always corresponding to the less smooth surface.

- PLA fiber blend with cotton fiber as the contact material was also shown to be the one with lower amplitude values, meaning a more homogeneous surface.

- Testing of the fabric surface where cotton fiber was the main contact material, regardless of the fabric blend, always resulted in the highest friction coefficient, corresponding in each pair, to the smoother surface. When cotton was combined with SPF, the results of friction were the highest, corresponding in this case to the smoothest of all surfaces.

- The Scheffe analysis demonstrated that there were three different subsets among the tested samples. A detailed study of the multiple comparison analysis table showed that the mean difference obtained between CO-SPF_OF and PES/CO-CO_IF was only 0.048 , a value very close to the 0.05 level of significance in which the test was carried out. This showed that this sample probably belonged to the last group of the CO-SPF_OF sample.

\section{Acknowledgements}

The authors express their gratitude to Carlos Alberto Guimarães and João Gonçalves, students of Apparel Engineering at the University of Minho, Portugal, for carrying out the experimental work.

\section{Literature Cited}

1. Kawabata, S., Niwa, M., and Wang, F., Objective Hand Measurement of Nonwoven Fabrics, Textile Res. J. 64(10), 597-610 (1994).

2. Gupta, B. S., and El Mogahzy, Y. E., Friction in Fibrous Materials, Textile Res. J. 61(9), 547-555 (1991).
3. Kawabata, S., "The Standardisation and Analysis of Hand Evaluation," (2nd Edn.), Textile Machine Society of Japan, Japan (1980).

4. Nosek, S., Problems of Friction in Textile Processes, International Conference Textile Science 93, TU Liberec, Czech Republic (1993).

5. Bueno, M. A., Renner, M., and Durand, B., Tribological Measurement of the State of Surface Fabrics by a Contact and a Non-contact Method, In "Proceedings of the Conference Mechatronics '98," Sweden, pp. 703-708 (1998).

6. Behera, B. K., Comfort and Handle Behavior of Linen Blended Fabrics, AUTEX Res. J. 7(1), 33-47 (2007).

7. Ramkumar, S. S., Umrani, A. S., Shelly, D. C., Tock, R. W., Parameswaran, S., and Smith, M. L., Study of the Effect of Sliding Velocity on the Frictional Properties of Nonwoven Fabric Substrates, Wear 256(3-4), 221-225 (2004).

8. Lima, M., Vasconcelos, R., Cunha, J., Martins, J., and Hes, L., FRICTORQ, Fabric Friction Tester: a Comparative Study with KES, Autex 2005, Portoroz, Slovenia (2005).

9. Maria Inês Cabral Teles Borges de Araújo, Analysis of the Influence of the Weave Structure in the Friction Coefficient of Fabrics, Final Year Project, Apparel Engineering, University of Minho, Guimarães, Portugal (2006).

10. Lima, M., and Hes, L., Inventors/Authors, Portuguese Patent $\mathrm{N}^{\circ} 102790$, Title: Method and Instrument for the Measurement of the Coefficient of Friction in Flat Solid Materials (2002).

11. Ingeo ${ }^{\mathrm{TM}}$ Fibers (www.ingeofibers.com, on-line accessed in 2006).

12. Fabric link (www.fabriclink.com/university/planfiber.cfm, online accessed in 2007)

13. www.fgtex.com.

14. Swicofil (www.swicofil.com/soybeanproteinfiber.html, on-line accessed in 2007).

15. Harvest SPF Textile Co., Ltd. (www.spftex.com, on-line accessed in 2006).

16. Lima, M., Silva, L. F., Vasconcelos, R., Martins, J., and Hes, L., FRICTORQ, Tribometer for the Objective Evaluation of Textile Surfaces, III Iberian Congress of Tribology, IBERTRIB, University of Minho, Guimarães, Portugal (2005).

17. Lima, M., Vasconcelos, R., Silva, L. F., and Martins, J., FRICTORQ, Innovation in the Objective Measurement of Friction in Textiles and Paper, Revista Nova Têxtil 78, 39-44 (2006).

18. Lima, M., Hes, L., Vasconcelos, R., and Martins, J., FRICTORQ, Accessing Fabric Friction with a Novel Fabric Surface Tester, AUTEX Res. J. 5(4), 194-201 (2005).

19. Lima, M., Hes, L., Vasconcelos, R., and Martins, J., FRICTORQ, a Novel Fabric Surface Tester: a Progress Report, $J$. Textile Eng. 51(3/4), 40-46 (2005). 